\title{
Choice of system boundaries in life cycle assessment
}

\author{
Anne-Marie Tillman, Tomas Ekvall*, Henrikke Baumann \\ and Tomas Rydbergt \\ Technical Environmental Planning, Chalmers University of Technology, S-412 96 \\ Göteborg, Sweden \\ *Chalmers Industriteknik, Chalmers Teknikpark, S-412 88 Göteborg, Sweden \\ tChemical Environmental Science, Chalmers University of Technology, S-412 96 \\ Göteborg, Sweden
}

\section{Received 27 January 1993; revised 29 December 1993}

\begin{abstract}
System boundaries in life cycle assessments (LCA) must be specified in several dimensions: boundaries between the technological system and nature, delimitations of the geographical area and time horizon considered, boundaries between production and production of capital goods and boundaries between the life cycle of the product studied and related life cycles of other products. Principles for choice of system boundaries are discussed, especially concerning the last dimension. Three methods for defining the contents of the analysed system in this respect are described: process tree, technological whole system and socio-economic whole system. The methods are described in the application's multi-output processes and cascade recycling, and examples are discussed. It is concluded that system boundaries must be relevant in relation to the purpose of an LCA, that processes outside the process tree in many cases have more influence on the result than details within the process tree, and that the different methods need to be further compared in practice and evaluated with respect to both relevance, feasibility and uncertainty.
\end{abstract}

Keywords: life cycle assessment; inventory; system boundaries

\section{Introduction}

Life cycle assessment (LCA) is a method for analysing and assessing the environmental impact of a material, product or service throughout its entire life cycle. In the first section of an LCA, the goal of the study is defined. In the inventory section, the environmental loadings, i.e. emissions, waste and use of resources, of the life cycle are identified, quantified and calculated per functional unit ${ }^{1}$. Further interpretation is done in an impact assessment.

LCAs are comparative studies, e.g. comparisons of different products performing the same function, different process alternatives or different waste-handling alternatives. LCAs may be performed as absolute studies of individual products with the aim of performing an improvement analysis ${ }^{2}$, which, in itself, is a comparative process. Comparisons with 'zero alternatives' are possible, in order to examine the consequences of introducing a new product or banning an existing product without a substitute ${ }^{3}$. The comparative nature of LCA studies requires equivalent definition of the system boundaries for the alternatives

0959-6526/94/01/0021-09

(C) 1994 Butterworth-Heinemann Ltd compared, and also requires that system delimitations are made with respect to which comparison is made in the study, i.e. the goal definition.

The methodological importance of definition of system boundaries has been shown by a number of studies $^{4-8}$. The ultimate system boundary is between the technological system and nature. Ideally, all the inputs and outputs necessary to the function of a product should be followed upstream and downstream to flows of energy or matter: (a) from nature to the technological system; and (b) from the technological system to nature. In accordance with Heintz and Baisnee, these flows are henceforth referred to as elementary flows ${ }^{8}$.

If all flows are followed until they have been reduced to elementary flows, this would result in systems too large and complex to describe and evaluate. Delimitations within the technological system must be decided on. One obvious simplification is to exclude from the system all activities that have negligible effects on the results. Activities that are identical in the compared alternatives can also be omitted.

System boundaries must be specified in many dimensions: 
- boundaries between the technological system and nature

- geographical area

- time horizon

- production of capital goods

- boundaries between the life cycle of the studied product and related life cycles of other products.

This article discusses different principles for choice of system boundaries, especially concerning the boundaries between the life cycle of the product studied and related life cycles of other products. The concept 'product $\mathbf{P}$ ' is used to describe the function of a product, service or material.

\section{Boundaries between the technological system and nature}

The life cycle begins with the acquisition of raw materials or energy carriers. For deposits, i.e. nonrenewable resources, the life cycle starts with the extraction of the natural resource, or the prospecting, which may also be included. For fund resources, such as farmland, forests and animals ${ }^{9}$, the harvest should be included as well as the activities needed to produce the harvest, such as ploughing, planting, fertilizing and use of pesticides. For flowing resources, e.g. solar radiation and running water ${ }^{9}$, the activities needed to bring the resources into the technological system should be included.

The end of the life cycle is when heat or waste in solid, liquid or gaseous form is released to receiving soil, water or air. Released substances may react to secondary products where they are received, or may be transported between different environmental compartments, which has to be considered in the impact assessment. Impacts on the technological system caused by pollutants, e.g. corrosion caused by acidic deposition, are not described in the inventory, but may be considered in the impact assessment.

Waste-water treatment plants and incineration plants are part of the technological system, and thus should be included in the system considered in the inventory, with the effluents seen as the result of the inventory.

Whether or not to include landfills in the technological system considered in the inventory is a question of time perspective. Landfills in operation are managed technologically, e.g. through treatment of leach water. However, in time they will be left unmanaged, their contents thus returned to the environment. Landfills have been treated as the final receiving site in most published LCAs. Emissions from landfills have been considered neither in inventories nor in impact assessments, which is unsatisfactory. Depending on time perspective, they may be included in the technological system, and their emissions included as the input to the impact assessment. It is also possible to regard solid waste in various classes as a final result of the inventory, provided that the impact assessment considers further reactions in, and transports from, the landfill. Exactly where to draw the line between the inventory and the impact assessment is an arbitrary choice, as long as there is a useful interface between the different sections of the LCA.

\section{Geographical area}

Geography plays a role in LCAs, in the following ways:

- the various parts of a product may be produced anywhere in the world;

- infrastructure, such as electricity production, waste management and transport systems, differs in different regions;

- the sensitivity of the environment to pollutants varies from one area to another.

An LCA must somehow be geographically restricted. The consumption of a product in a certain area may be used as one geographical delimitation. It allows for production outside the defined area, but use and waste management are confined to the defined area. Other delimitations are adequate for other purposes, e.g. an LCA of a specific product, produced on a specific site, but used and treated as waste in the product's market regions.

\section{Time horizon}

LCAs are made because we are concerned about the present and future environmental impact of presentday production and consumption of products. Hence, they should be focused more on the present and future environmental impact, than on the impact that has already occurred. However, prior levels of pollution are important when assessing the effects of presentday emissions.

The time horizon of the inventory is restricted to the timespan during which the technology can be surveyed. The lifetime of the product must be considered when deciding the time horizon.

Often, pollutants have an impact during a longer period of time than can be covered by the inventory. Hence, the impact assessment ought to look further into the future than the inventory, taking into account future effects of present-day emissions.

\section{Capital goods}

Whether or not to include capital goods must be decided in relation to the goal definition. If the LCA's major objective is future environmental effects resulting from present production and consumption, investments made in the past are of little interest.

However, an LCA may analyse whether it is environmentally beneficial to invest in new process equipment in order to reduce emissions from a process. To answer such a question it is necessary to compare the production and operation of the new equipment with continued use of the existing equipment. The 
approach is similar to that of an economic investment analysis.

The conclusion of the Society of Environmental Toxicology and Chemistry (SETAC) workshop in Leiden $^{10}$ was that the production of capital goods should be included only when the investments are clearly and significantly different in compared alternatives. This is consistent with the principle of excluding identical activities.

\section{Boundaries between the life cycle of the product studied and related life cycles}

Most activities in the global technological system are interrelated. Boundaries must be set between the life cycle of the product studied and other associated life cycles. Methodological difficulties are encountered when dealing with processes with multiple products, cascade recycling (open loop recycling) and waste treatment processes, which have input consisting of many different products. For waste treatment processes the problem is the lack of knowledge rather than the definition of system boundaries.

We have identified and characterized three principal methods for defining the contents of the system, from smaller to larger:

- process tree

- technological whole system

- socio-economic whole system.

\section{Process tree}

The process tree (PT) system only includes processes and transportation directly involved in the production, use and disposal of the product studied, the ancillary materials and the equipment. All flows are followed upstream, to the acquisition of raw materials or other resources. When more than one product is produced, the environmental loadings are distributed among the product studied and its by-products or other secondary functions, according to certain rules of allocation. Only the main stream is followed downstream, to elementary flows. Comparisons are made between systems fulfilling one single function.

\section{Technological whole system}

The technological whole system (TWS) includes all processes and transports affected by the choice between the alternatives compared, assuming that the demand for the functions fulfilled by the systems is constant. This means that economic and social forces are ignored. The method has relevance for treatment of processes with multiple products and cascade recycling. The advantage is that compared systems fulfil the same functions. The method is similar to that discussed by Heintz and Baisnée ${ }^{8}$.

\section{Socio-economic whole system}

The socio-economic whole system (SWS) includes the same processes and transports as the TWS method but, in addition, considers economic forces and social factors. This may lead to further expansion of the system. Although effects of socio-economic factors are taken into account, the objective of the analysis is restricted to influence on the environment, in contrast to the 'Produktlinienanalyse' method which, in addition, investigates influence on society ${ }^{11}$. The results of a life cycle inventory are expressed in terms of environmental loadings per functional unit. The comparison between alternatives is usually done using the functional unit as the basis for comparison. In an SWS, the number of functional units, i.e. the production volume, may vary between alternatives compared. In such cases, the functional unit, being the basis for calculation, cannot be used as the basis for comparison. Instead, the basis for comparison may be the total production volume under study or the consumption of the product in a certain geographical area. Thus, SWS methods may be used to study the effects of a change in production volume, including comparisons with 'zero' alternatives.

\section{Applications \\ Multiple functions}

Figure 1 describes a comparison of product A with product $\mathrm{C}$, both fulfilling the same function. Product $A$ has a by-product, $B$. To calculate the environmental loadings associated with product $A$, a method is needed to relate the environmental loadings to the different products.

It is most common to use the PT method, allocating the loadings to the different products in proportion to their weight fraction or another physical property ${ }^{12,13}$ or in proportion to their economic value ${ }^{14}$. Sometimes the loadings are allocated entirely to the product studied $^{12}$. Huppes ${ }^{14}$ argues that allocation should reflect the objective of the process, which is to create value, based on all the functions the process helps to fulfil. According to this, physical causation as the overruling principle for allocation does not make sense. Function has, however, been used implicitly, disguised as a physical approach. Huppes makes a distinction between joint processes, where production of $A$ is a prerequisite to the production of $B$, and

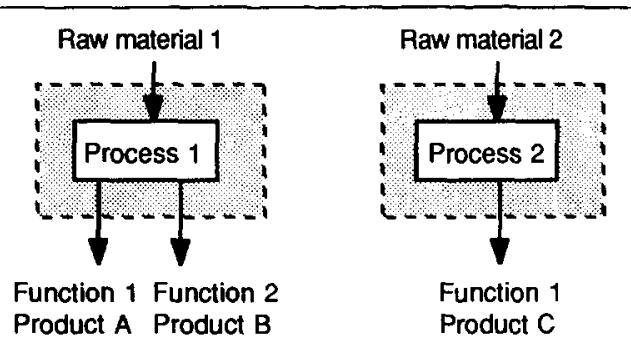

Figure 1 Comparison of product $\mathbf{A}$, produced in a multi-output process, with product $\mathrm{C}$, using the process tree method 
combined processes where A and B can be produced in separate processes. For joint processes, allocation should be based on gross sales value, whereas for combined processes allocation should be based on physical causation. Overheads, i.e. in-firm services, should be allocated on the basis of the gross sales value.

Heintz and Baisnée ${ }^{8}$ propose that different rules be applied to co- and by-products, while calling for a clearly stated distinction between the two categories. For co-products, allocation should always be used, whereas for by-products, allocation may be used or the system may be compensated for alternative production of the by-product. This system compensation may be regarded as a TWS.

When using the TWS method, allocation is not necessary, since systems with comparable functions are compared. A process that produces only product $B$ can be added to the production of product $C$, as described in Figure 2a. The compared systems now have the same functions. In order to describe the environmental loadings per individual functional unit, it is possible to describe the systems as in Figure $2 b$. The relevance of a TWS depends on the existence of technically and economically feasible alternative processes for the production of the by-product. For instance, if the by-product is heat, there are many feasible alternative ways to produce heat. Industrial scrap that is not recycled into the production process it emanated from, but into other products, can be regarded as a by-product. In this case the alternative production (process 3 ) would be the same as process 1. For many other processes, alternative production of by-products is less feasible, for instance with regard to alternatives to oil refineries or electrolysis of sodium chloride to chlorine and sodium hydroxide. One may also end up with systems that are too large to

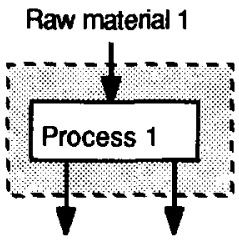

Function 1 Function 2 Product A Product B

a

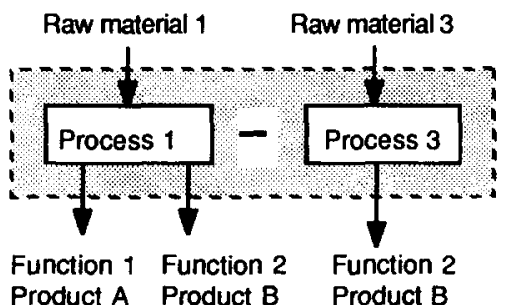

b
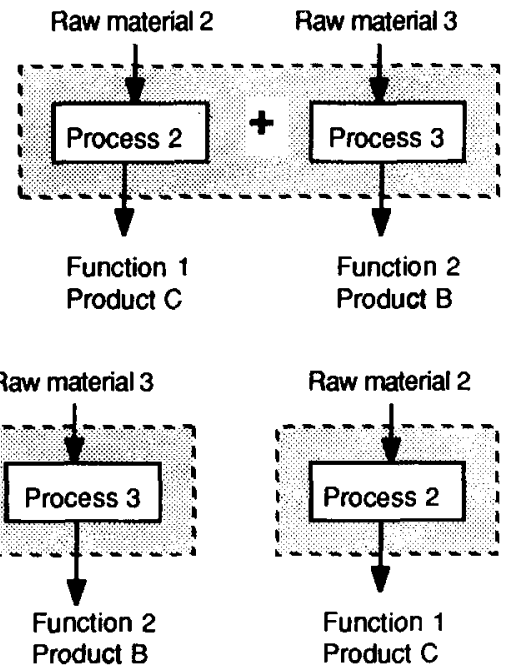

Figure 2 Comparison of product A, produced in a multi-output process, with product $\mathrm{C}$, using the technological whole system method handle, and perhaps irrelevant, e.g. if the alternative production itself generates by-products, so that additional alternative processes have to be considered.

Figure $3 a$ shows an example where the production of $A$ and $B$ using process 1 is much less expensive than the production of $C$ and $B$ in separate processes. Taking economic forces into consideration, the total production volume may be larger for the first alternative. This is accounted for only in the SWS method.

The SWS method can also handle systems as described in Figure $3 b$, where $\mathbf{B}$, as produced by process 3 , becomes so expensive that in a market situation it would be replaced by another product, D.

\section{Cascade recycling}

Cascade recycling means that a product, after having fulfilled one function, is recycled into another function, while quality is reduced. Examples are:

- reuse with lost quality, e.g. poly(ethylene terephthalate) (PET) bottles that can be filled with mineral water only on their first cycle;

- material recycling with loss of quality;

- energy recovery from waste, since the heat comes from materials that have already served one purpose.

In an LCA designed to investigate whether or not a certain cascade recycling system is environmentally beneficial, the system boundaries are defined as in Figure 4.

When the purpose is to study the environmental loadings associated with one of the products in the cascade, defining the system boundaries becomes more difficult. It has been proposed to distribute the effects of recycling among the products in the cascade, based on physical properties ${ }^{2,13}$. This method requires information about the whole cascade, but in reality often only one product system in the cascade is
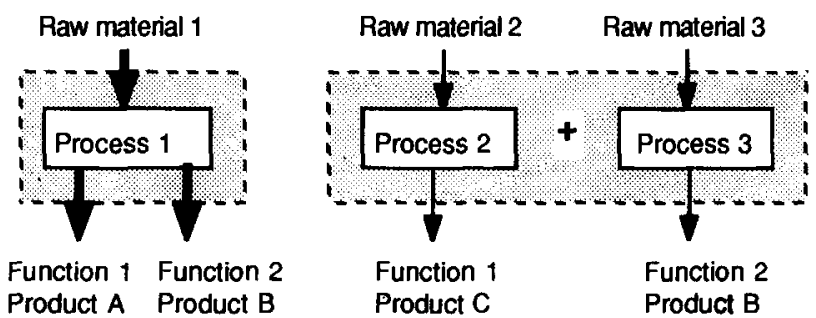

Function 1 Function 2 Product A Product B

a
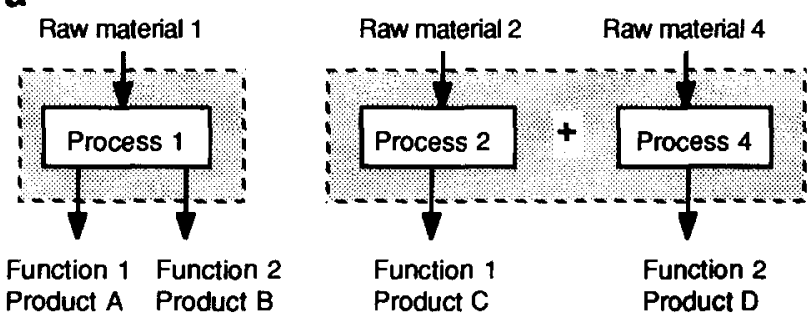

b

Figure 3 Comparison of product $\mathrm{A}$, produced in a multi-output process, with product $\mathrm{C}$, using the socio-economic whole system method (thick arrows indicate increased flow) 

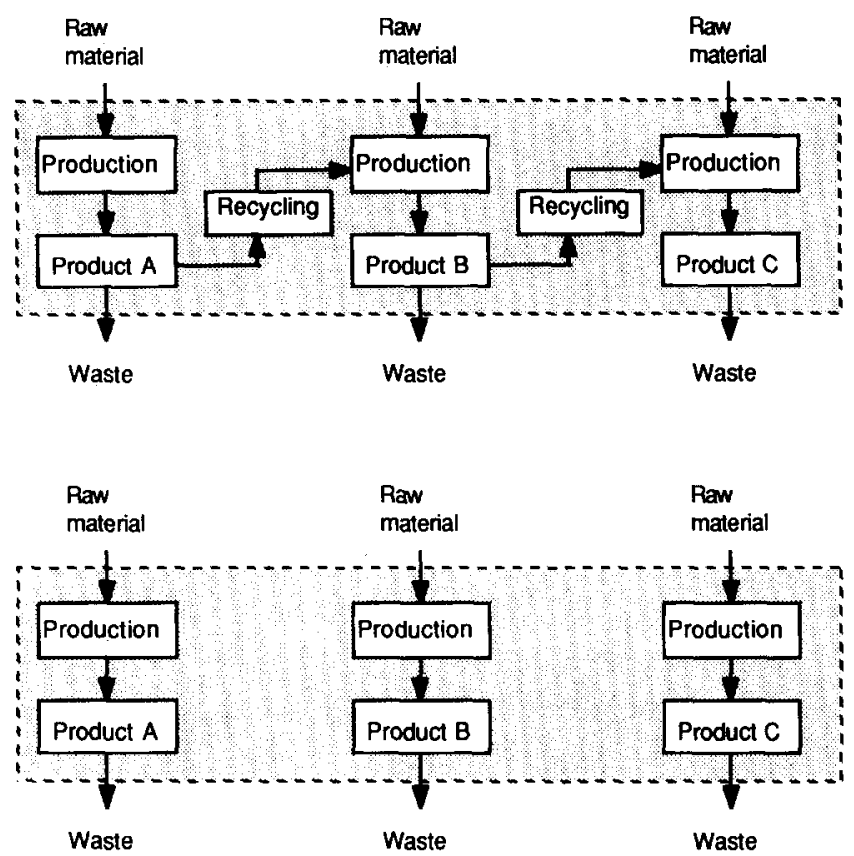

Figure 4 Comparison of cascade recycling system to production from virgin raw materials

known. There are several possible ways to handle this information problem, as detailed below.

1. Approximation of the cascade with closed loop recycling, especially when the material quality loss is small or the number of steps in the cascade is large. When the fraction of recycled material in the product differs from the fraction being collected for recycling, the difference leaves the system as a non-elementary flow 15

2. Approximation of the cascade with closed loop recycling, compensating for quality degradation by introduction of a 'phased degradation factor', which deducts the primary production saved ${ }^{16}$.

3. Separation of the different product systems in the cascade. Only the product system of the product studied is investigated and the other products in the cascade are not considered. Recycled and recyclable materials cross system boundaries as non-elementary flows. The effects of recycling are implicit. The method has the advantage of giving modular product systems. When added up, the total loadings are those of the cascade. Several studies ${ }^{2,12,13,15}$ suggest that the separation be made just before the recycling process. The recycling process becomes the 'raw material extraction' of the next product in the cascade. Huppes ${ }^{14}$ suggests that the point of separation is based on the value of the material stream. Processes are included up to the point where the value of the material begins to increase.

4. Separation of the different product systems in the cascade through introduction of material pools, situated outside the system boundary ${ }^{17}$ (see Figure 5 ). The concept of material pools has been introduced implicitly in methods where recycled or recyclable materials cross system boundaries as

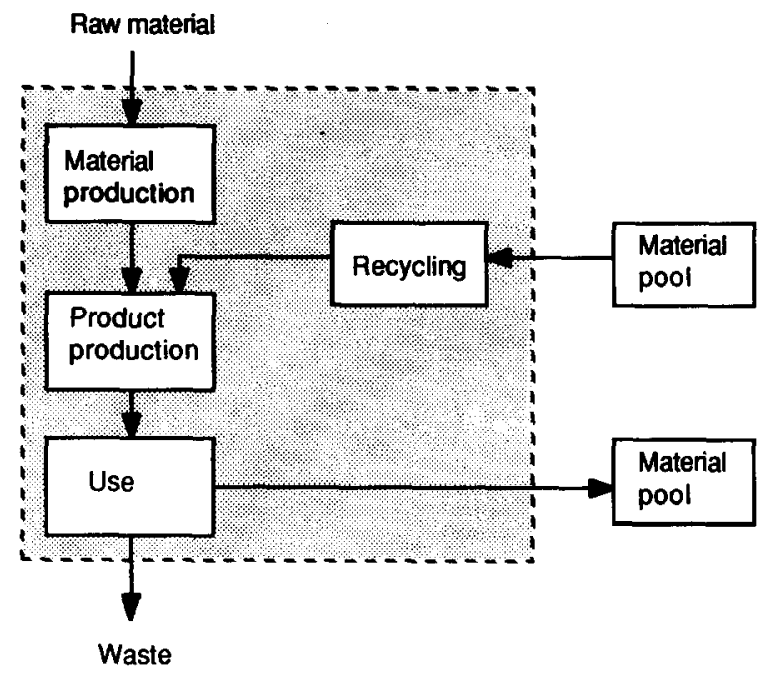

Figure 5 System with external material pools

non-elementary flows. The material in the pool is given an intrinsic 'environmental value' expressed in terms of environmental loadings. Material pools with different qualities have different 'environmental values'. Taking material from a material pool costs 'environmental value' and delivering material to a pool results in a credit.

The 'environmental value' of the material pool can be established using the TWS method. It may be given the value of the difference between virgin production and reprocessing to the original quality. This leads to an allocation of the loadings from the virgin production in proportion to the quality degradation caused by each product in the cascade. The material pool may also be given an 'environmental value' in relation to its secondary use. An example would be to give a combustible material the value of the difference between incinerating the material and production of the equivalent amount of heat from an alternative fuel. Different methods are probably applicable for different types of materials. The method needs further development.

An example of a TWS, designed to calculate the environmental loadings of product $B$, is shown in Figure 6. Using the TWS and SWS methods, the effects of recycling are fully described, at the expense of modularity. The effects of recycling are fully allocated to the product under study. The SWS method requires information about the whole cascade, whereas the TWS method requires information about the product systems adjacent to the product system studied.

\section{Examples}

Waste incineration with energy recovery

Consider an environmental comparison of two processes for waste treatment: incineration with energy recovery, and landfill deposit. With the system boundaries confined to the PT, the alternatives compared 


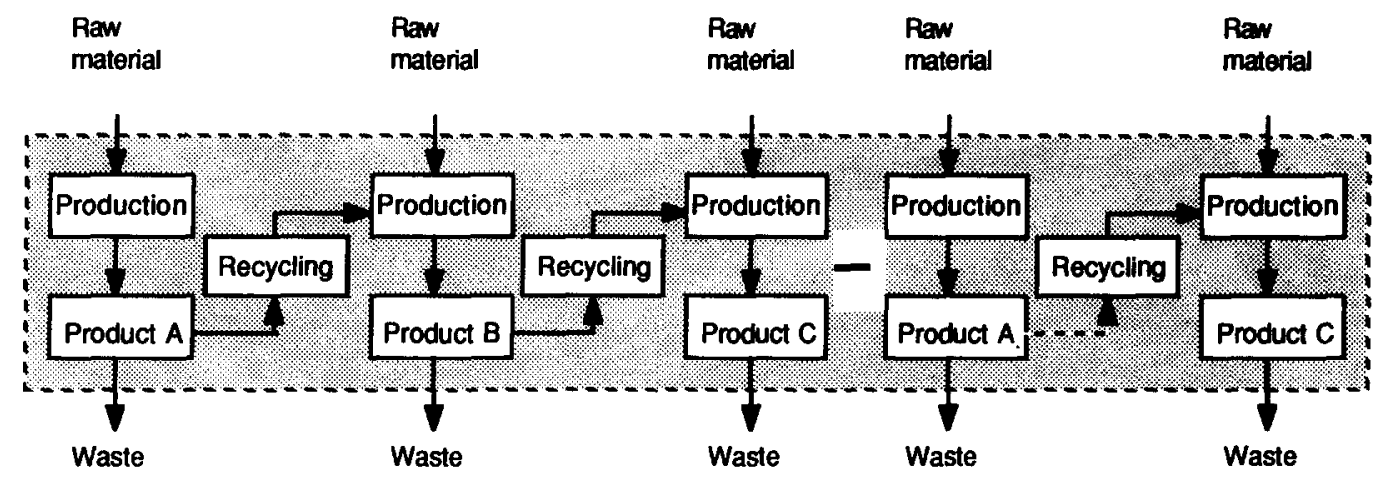

Figure 6 System boundaries used to calculate the environmental loadings associated with one of the products in a cascade, product B, using the technological whole system method

will be described as in Figure 7. The emissions from the incinerator are allocated between its two functions: waste elimination and heat generation.

It is common to allocate all emissions from the incineration to the product studied, while the recovered energy is subtracted from the overall energy consumption of the life cycle. This is presumably based on the assumption that different forms of energy are interchangeable, i.e. that the recovered energy could, in principle, be used in earlier processes in the life cycle. However, if heat from the incinerator were to be used in earlier production steps, fuels would be replaced in these steps and hence emissions from burning of fuels would be avoided, which is often not taken into account.

The TWS method demands that compared systems fulfil the same functions. To achieve this, an alternative combustion process can be added to the landfill. Systems with a single function can be obtained through subtraction of the alternative combustion process from the incineration, as described by Heintz and Baisnée ${ }^{8}$ and Tillman et al. ${ }^{18}$ (see Figure 8). The method must be supplemented with a choice of margin in order to establish which is the alternative fuel. It has been shown that the inclusion of alternative combustion has a profound influence on the results of $\mathrm{LCAs}^{4,5}$.

In an SWS, the amount of saved fuel is not necessarily equivalent to the amount of heat produced
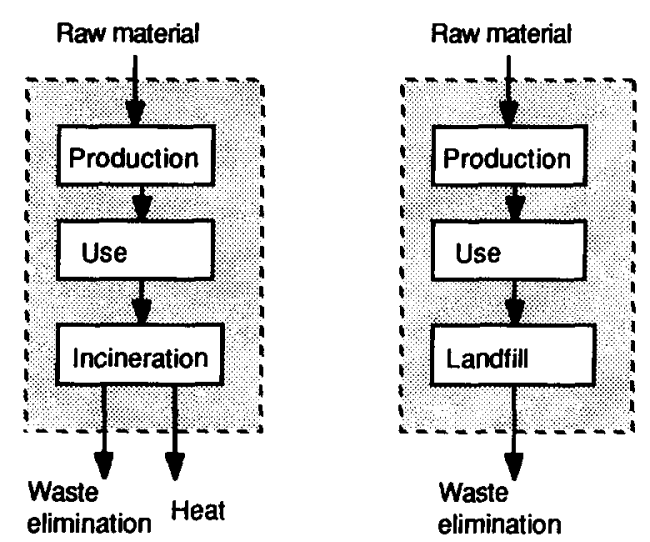

Figure 7 Comparison of incineration and landfill, using the process tree method
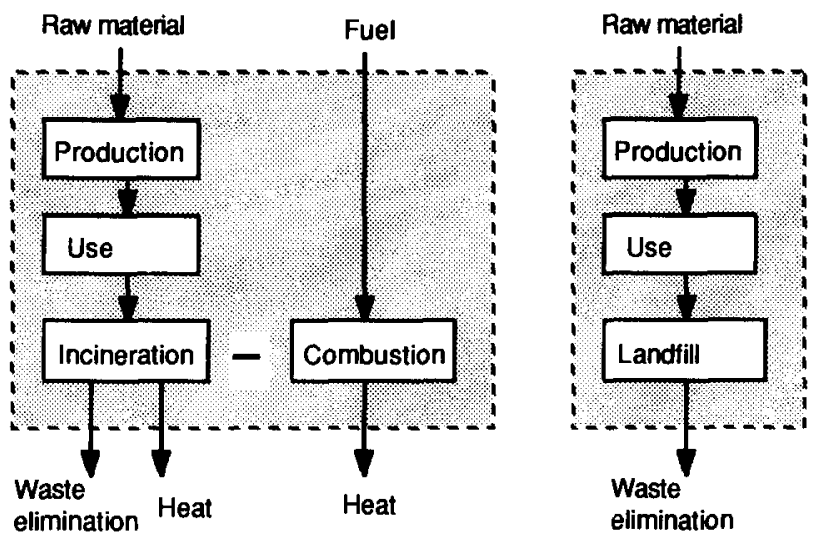

Figure 8 Comparison of incineration and landfill, using the technological whole system method

from waste incineration, as it is in a TWS (see Figure 9). If heat from waste incineration is produced at a lower cost than heat from other sources, this may result in a higher consumption of heat.

\section{Milk packaging}

Consider the question: which is the environmentally preferable milk packaging system, disposable, polyethylene-coated cartons or returnable polycarbonate bottles? The polycarbonate bottles are not only reused,
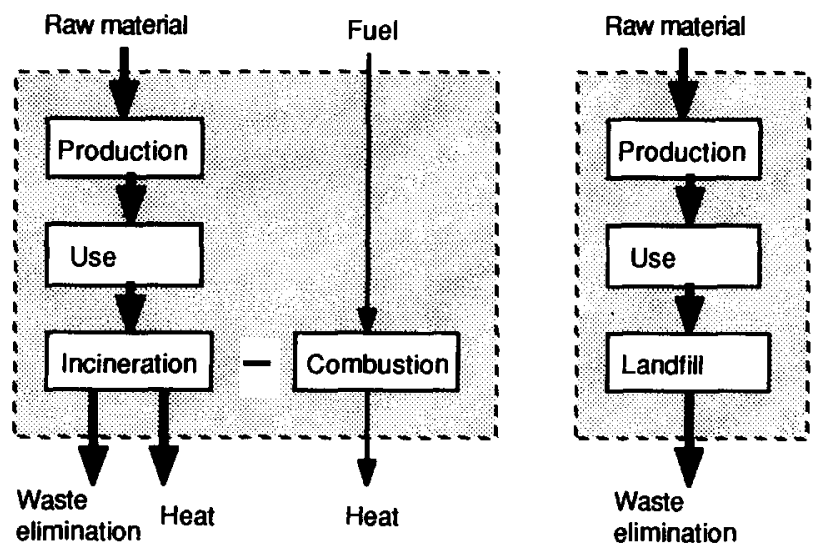

Figure 9 Comparison of incineration and landfill, using the socioeconomic whole system method (thick arrows indicate increased flow) 

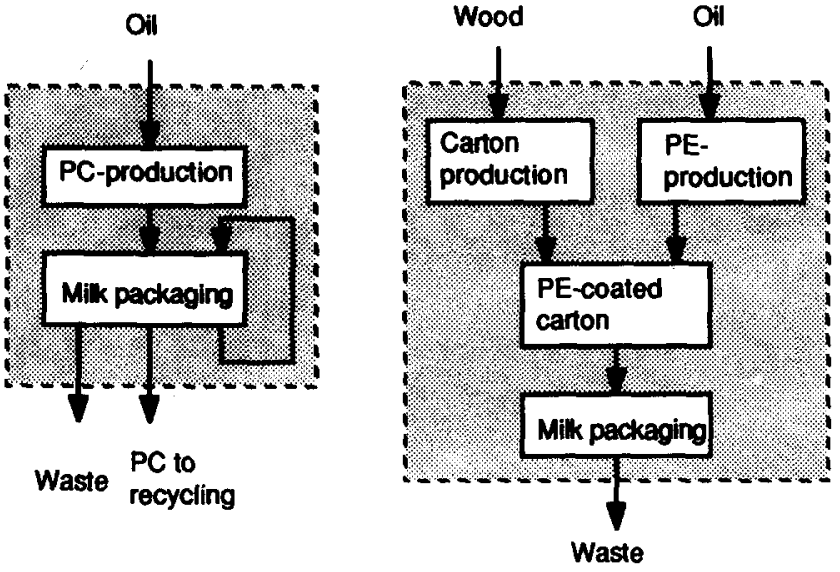

Figure 10 Comparison of milk packaging using the process tree method: returnable polycarbonate (PC) bottles and polyethylene (PE) coated carton

they are recycled to electrical equipment after their final cycle. In the PT method, allocation between the two functions of the polycarbonate is necessary (see Figure 10).

If the polycarbonate system is widened to include both functions of the polycarbonate, milk packaging and electrical equipment, no allocation between primary and secondary product is necessary. To make the systems comparable, an electrical equipment function has to be added to the carton system. The systems, as drawn in Figure 11, fill several functions. This may be accepted, or an independent production of electrical equipment may be subtracted from the polycarbonate system rather than added to the carton system.

It is probable that the consumption of milk is affected by both the price of milk packaging and the extra work for the consumer to return the bottles. As a consequence, the life cycle of the milk has to be included in an SWS (see Figure 12). It is difficult to define a basis of comparison when the system is widened to include socio-economic forces. The volume of milk is now a variable, and thus the functional unit cannot be used as a basis of comparison. The
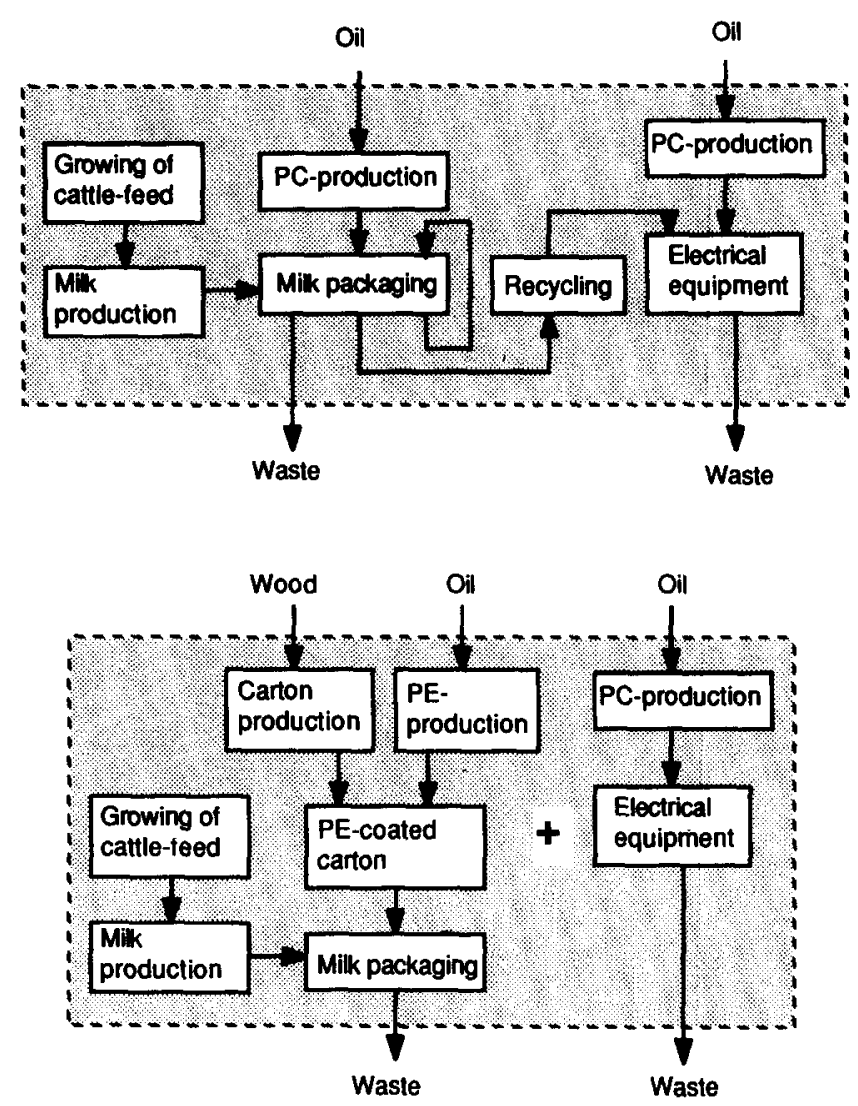

Figure 12 Comparison of milk packaging using the socio-economic whole system method: returnable polycarbonate (PC) bottles and polyethylene (PE) coated carton

environmental loadings may instead be calculated for the whole volume of milk under study.

\section{Discussion and conclusions}

The main objective when defining system boundaries must be to include in the system the activities relevant to the purpose of the study. Hence, choice of system boundaries is closely related to the goal definition.
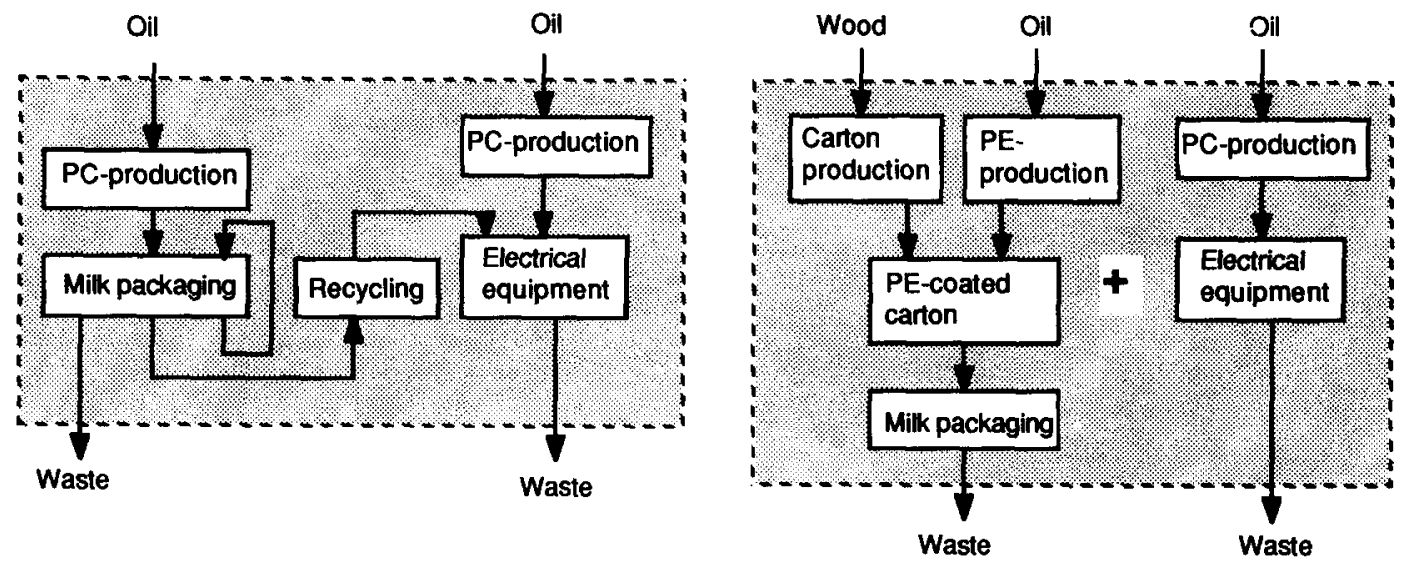

Figure 11 Comparison of milk packaging using the technological whole system method: returnable polycarbonate (PC) bottles and polyethylene (PE) coated carton 
For example, the scale of change under study must be considered, whether it is a marginal change within an existing technology, or a change of a whole technology.

A number of practical aspects limit how large and complex a system may be analysed. Among these are the resources available for LCAs and the availability of data. A larger system contains more uncertainties than a smaller one, both in data and in assumptions concerning surrounding conditions. If the uncertain assumptions are few, this can be dealt with through analysis of several scenarios based on different assumptions.

Process tree methods are always applicable, but include subjective choices concerning allocation method. They give modularity, suitable for databases and accounting systems, designed to describe which environmental loadings a product can be made responsible for. Through allocation, multifunctional systems are made virtually monofunctional systems. PT methods do not describe the full environmental difference between the alternatives studied, since systems compared do not truly fulfil the same functions.

Technological whole systems are feasible when technically and economically realistic alternative processes exist. They are important, since it has been shown that processes outside the process tree often have more influence on the results than details within the process tre $e^{4,5}$. If relevant in relation to the goal definition, they may even include alternative uses of renewable raw materials, saved through recycling. Whole system approaches are useful for investigations of the effects of a change, e.g. change of raw material, production process or waste treatment process, since effects on surrounding conditions can be dealt with. They may be combined with PT methods, in such a way that TWS methods are used for the parts of the life cycle that are central to the investigation, while PT methods are used for other parts of the life cycle. In whole-system approaches, the environmental difference between the alternatives compared is fully described, at the expense of modularity, which makes them suitable for investigations of the effects of a change.

Pure socio-economic whole systems are probably rarely feasible, owing to their size, complexity and a multitude of uncertain assumptions. However, certain aspects of SWS systems may be considered important and thus included in an LCA, e.g. differences in production volume in alternatives compared.

There are no objective means of calculating the environmental loadings of one single product in a cascade. Methods that separate the different product systems in the cascade, with or without introduction of material pools, do not require knowledge of the whole system, as other methods do. Separation of the different product systems in the cascade gives modular systems, suitable for databases and accounting systems. If no material pool is used, the method gives a strong incentive to recycling of used materials, but less incentive to production of recyclable products. With the introduction of a material pool, given an intrinsic 'environmental value', there is a stronger incentive to produce recyclable products, but less incentive to recycle used materials. However, the question of which incentives are implicit in the different methods also depends on the valuation method, on how waste is valued in relation to other environmental loadings. In whole-system approaches the effects of recycling are fully described, at the expense of modularity.

The different methods need to be compared in practice and evaluated with respect to relevance, feasibility and uncertainty, and also with respect to which incentives are implicit in the various methods.

\section{Acknowledgements}

Financial support from the Nordic Council of Ministers and the Swedish Waste Research Council is gratefully acknowledged.

\section{References}

1 Assies, J.A. in 'Life Cycle Assessment', Workshop report, Leiden, The Netherlands, 2-3 December 1991, Society of Environmental Toxicology and Chemistry, Brussels, 1992, pp. 1-20

2 Fava, J.A. et al. (Eds) 'A Technical Framework for Life-Cycle Assessment', Workshop report, Vermont, 18-23 August 1990, Society of Environmental Toxicology and Chemistry (SETAC) and SETAC Foundation for Environmental Education, Washington, DC, 1991

3 Klöpffer, W. in 'Life Cycle Assessment', Workshop report, Leiden, The Netherlands, 2-3 December 1991, Society of Environmental Toxicology and Chemistry, Brussels, 1992, pp. $29-33$

4 Baumann, H., Ekvall, T., Eriksson, E., Kullman, M. Rydberg, T., Ryding, S.-O., Steen, B. and Svensson, G. 'Miljömässiga skillnader mellan återvinning/återanvändning och förbränning/deponering', Reforsk FoU nr 79, Malmö, 1993

5 Ekvall, T. 'Life-cycle Analysis of Corrugated Cardboard a Comparative Analysis of Two Existing Studies', CIT Ekologik 1992:3, Göteborg, 1992

6 Ekvall, T., Baumann, H., Svensson, G., Rydberg, T. and Tillman, A.-M. in 'Product Life Cycle Assessment Principles and Methodology', Nord 1992:9, Nordic Council of Ministers, Copenhagen, 1992, pp. 132-171

7 Benda, J. and Narayan, R. 'Life Cycle Analysis: A Marketing Nightmare', Paper presented at Cellulose ' 91 , New Orleans, 2-6 December 1991

8 Heintz, B. and Baisnée, P.-F. in 'Life Cycle Assessment', Workshop report, Leiden, The Netherlands, 2-3 December 1991, Society of Environmental Toxicology and Chemistry, Brussels, 1992, pp. 35-52

9 Månsson, B. 'Miljö för bärkraftighet', Liber-Hermods, Malmö, 1993

10 Huisingh, D. in 'Life Cycle Assessment', Workshop report, Leiden, The Netherlands, 2-3 December 1991, Society of Environmental Toxicology and Chemistry, Brussels, 1992, pp. $71-72$

11 Osnowski, R. and Rubik, F. (Eds) 'Produktlinienanalyse: Bedürfnisse, Produkte und ihre Folgen', Kölner Volksblatt Verlag, Köln, 1987

12 Fecker, I. 'How to Calculate an Ecological Balance?', Report No. 222, EMPA, St. Gallen, 1992

13 Vigon, B.W., Tolle, D.A., Cornaby, B.W., Latham, H.C., Harrison, C.L., Boguski, T.L., Hunt, R.G. and Sellers, J.D. 'Life-Cycle Assessment: Inventory Guidelines and Principles', EPA/600/R-92/036, US Environmental Protection Agency, Cincinnati, 1992

14 Huppes, G. in 'Life Cycle Assessment', Workshop report, 
Choice of system boundaries in LCA: A.-M. Tillman et al.

Leiden, The Netherlands, 2-3 December 1991, Society of Environmental Toxicology and Chemistry, Brussels, 1992, pp. $57-70$

15 Lübkert, B., Virtanen, Y., Mühlberger, M., Ingman, J., Vallance, B. and Alber, S. 'IDEA. An International Database for Ecoprofile Analysis. A tool for Decision Makers', International Institute for Applied Systems Analysis (IIASA), Laxenburg, 1991

16 Heijungs, R., Guinée, J.B., Huppes, G., Lankreijer, R.M., Ansems, A.M.M., Eggels, P.G., van Duin, R. and de Goede, H.P. 'Manual for the Environmental Life Cycle
Assessment of Products', Second interim version, Centre of Environmental Science, Leiden University, Dutch Organisation for Applied Scientific Research, Fuels and Raw Materials Bureau, The Netherlands, 1991

17 Berglund, S. 'Livscykelanalys - Miljöhänsyn vid konstruktionsarbete', Department of Machine and Vehicle Design, Chalmers University of Technology, Göteborg, 1992 18 Tillman, A.-M., Baumann, H., Eriksson, E. and Rydberg, T. 'Life Cycle Analysis of Selected Packaging Materials. Quantification of Environmental Loadings', Offprint from SOU 1991:77, Chalmers Industriteknik, Göteborg, 1992 